\title{
Design of Intelligent Fault-Tolerant Flight Control System for Unmanned Aerial Vehicles
}

\author{
Yuta Kobayashi and Masaki Takahashi \\ Keio University \\ Japan
}

\section{Introduction}

Recently, unmanned aerial vehicles (UAVs) have gained worldwide attention. Because the safety of people on board does not need to be considered, small UAVs can easily be made for low-cost. Therefore, a UAV can be used to observe disasters, to surveil for a long time, and so on. However, it also has several disadvantages such as unreliability and worse performance in unexpected situations. Because small UAVs must be easily made for lowcost, adding a redundant on-board actuator or sensor in order to deal with unexpected situations is unsuitable. Thus, several researchers have proposed a flight control system using a software redundancy approach.

For fault detection, methods using multiple-model adaptive estimation (MMAE) (Guillaume Ducard \& Hans P. Geering, 2008), and system parameters (Mohammad Azam et al, 2005) have been proposed. However, because these methods design a model or parameters for only each assumed fault in designing, unexpected faults cannot be detected. On the other hand, another method discriminates between faults and natural disturbances like gusts of wind. (Jovan D. Boskobic et al, 2005) However, this is not easy because the expected disturbances are assumed in designing. Currently, the demand for a UAV flight control system is to discriminate between faults and natural disturbances fundamentally with a simple algorithm.

In this research, an intelligent flight control system was developed that can discriminate between faults and natural disturbances in order to evaluate and deal with the situation. In the proposed control system, an evaluator of flight conditions was designed on the basis of the dynamics of a controlled object. Moreover, to deal with the situation adaptively, a new flight-path-planning generator was introduced on the basis of the evaluation. In this study, each subsystem was designed by a neural network. Moreover, the learning-based systematical design method was developed that uses evaluation functions for the subsystems. To verify the effectiveness of the proposed flight control system, a six-degreeof-freedom nonlinear simulation was carried out.

\section{Aircraft motion}

The UAV treated in this research is a double-delta-wing UAV shown in Fig. 1. The coordinate system is defined in Table 1. The motion equation of an aircraft is derived from Newtonian dynamics. Six-degree-of-freedom nonlinear equation of motion is shown in Eq. (1). 


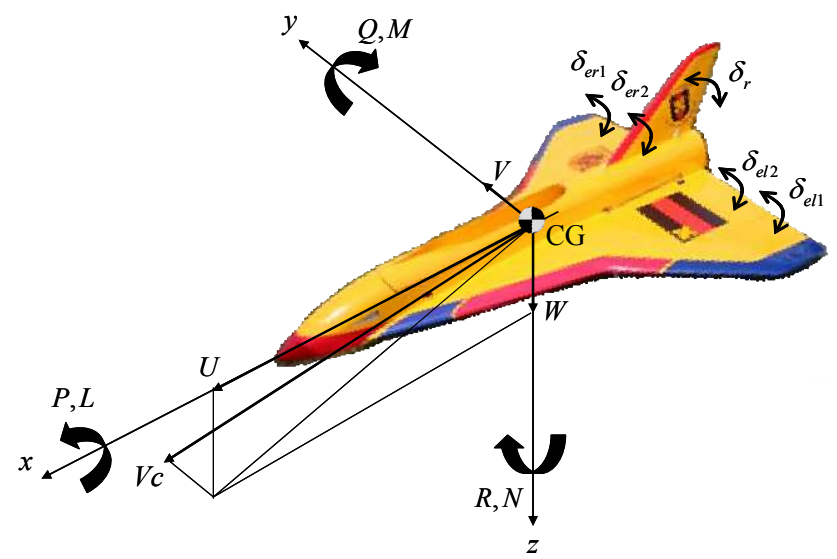

Fig. 1. Body axis

$$
\begin{aligned}
& X=m(\dot{U}+Q W-V R+g \sin \Theta) \\
& Y=m(\dot{V}+U R-P W-g \cos \Theta \sin \Phi) \\
& Z=m(\dot{W}+P V-U Q-g \cos \Theta \cos \Phi) \\
& L=\dot{P} I_{x}-\dot{R} J_{x z}+Q R\left(I_{z}-I_{y}\right)-P Q J_{x z} \\
& M=\dot{Q} I_{y}+P R\left(I_{x}-I_{z}\right)+\left(P^{2}-R^{2}\right) J_{x z} \\
& N=\dot{R} I_{z}-\dot{P} J_{x z}+P Q\left(I_{y}-I_{x}\right)+Q R J_{x z}
\end{aligned}
$$

In Eq. (1), $X, Y$, and $Z$ indicate each axis's external force term except for gravitational force (including aerodynamic force, thrust force). In addition, $\Phi, \Theta$, and $\Psi$ indicate Euler angle of each axis. The proper nonlinear model shown in Eq. (1) is used in the numerical simulation. In contrast, the linearized model based on Eq. (1) is used to design the controller. Many of parameters of motion equation are decided on the basis of the wind-tunnel experiment. The parameters that cannot be acquired in the experiment are estimated by the method using nonlinear function. (Kato et al, 1982)

Each elevon steerage angle of the double-delta-wing UAV is expressed in Eq. (2) by using elevator steerage angle $\delta_{e}$ and aileron steerage angle $\delta_{a}$.

$$
\begin{aligned}
& \delta_{e l_{1}}=\delta_{e l_{2}}=1 / 2\left(\delta_{e}+\delta_{a}\right) \\
& \delta_{e r_{1}}=\delta_{e r_{2}}=1 / 2\left(\delta_{e}-\delta_{a}\right)
\end{aligned}
$$

\section{Fault-tolerant system}

The block diagram of the proposed intelligent fault-tolerant flight control system is shown in Fig. 2. It is composed of fault detection, fault identification, and fault accommodation (FDIA). In this section, the brief summary of each system is represented. 


\begin{tabular}{c|c|c|c}
\hline \hline & $\begin{array}{c}\text { Velocity \& } \\
\text { Angular velocity }\end{array}$ & $\begin{array}{c}\text { External force \& } \\
\text { Moment }\end{array}$ & Distance \\
\hline Forward & $U$ & $X$ & $x$ \\
Starboard & $V$ & $Y$ & $y$ \\
Down & $W$ & $Z$ & $z$ \\
Roll & $P$ & $L$ & \\
Pitch & $Q$ & $M$ & \\
Yaw & $R$ & $N$ &
\end{tabular}

Table 1. Coordinate system and symbol

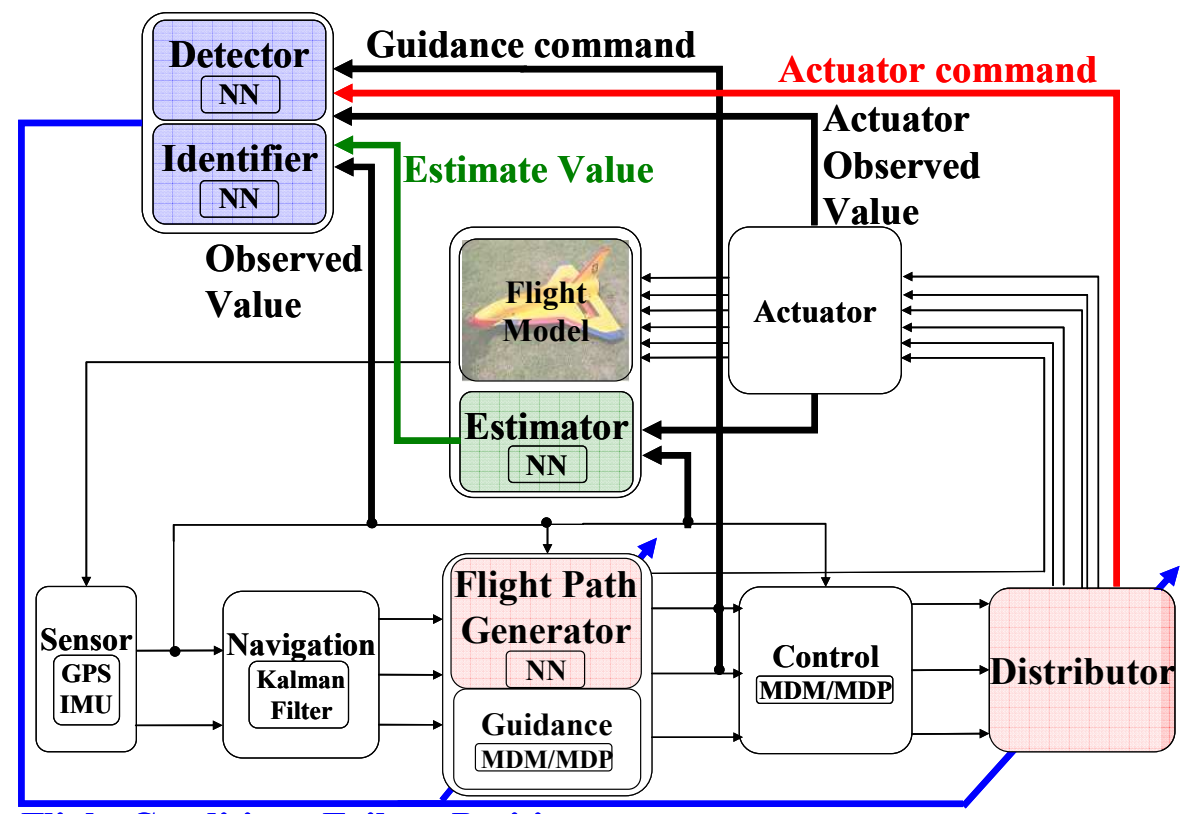

Flight Condition, Failure Position

Fig. 2. Block diagram of proposed flight control system

\subsection{Fault detection}

Fault detection is to distinguish faults from natural phenomena like gusts of wind. To achieve this, this research focused on how each influence on the dynamics of an aircraft, and then an estimator and a detector were designed. The estimator can estimate the ideal state of an UAV. The detector evaluates the flight conditions of an UAV by using the error information between the observed and estimated values.

\subsection{Fault identification}

Fault identification is to locate a broken actuator. To achieve this, an identifier was designed. Generally, to identify a fault, a method is used that sets a threshold value of error 
information between an actuator command and a steerage value. However, this method depends on designer's thought, and inevitably the design work gets into trial and error. By contrast, this research focused on the nonlinear mapping ability of a neural network to flexibly respond to changes.

\subsection{Fault accommodation}

Fault accommodation is to stabilize the flight conditions of an UAV when a fault emerges. To achieve this, a distributor and a flight path generator were designed. The distributor switches the distribution matrix that sends a control command to actuators on the basis of the location of a broken actuator. This countermeasure results in the maximum application of the remaining actuators. The flight path generator generates a new flight path which automatically takes account of both flight stability and following capability of mission trajectory on the basis of the evaluation result.

\section{Specific design of each component}

\subsection{Guidance and control}

In this research, a coupled motion between longitudinal and lateral-directional is controlled. This is because the roll angular velocity is controlled by limiting the derivative value of the bank angle command. Therefore, the motion of UAV can be separated into longitudinal and lateral-directional motions. In the guidance and control system, longitudinal guidance, lateral-directional guidance, longitudinal control, and lateral-directional control were designed separately. The guidance and control laws were designed by multiple delay model and multiple design point (MDM/MDP) method. The block diagram of longitudinal guidance, lateral-directional guidance, longitudinal control, and lateral-directional control are shown in Figs. 3 to 6.

\subsection{Estimator}

The estimator achieves nonlinear dynamics of the UAV approximately by using nonlinear mapping ability of feedforward-type neural network. It estimates next state vectors of the UAV from previous state vectors and actuator steerage commands.

The structure is three-layer neural network shown in Fig. 7. Input layer has 15 neurons, hidden layer has 18, and output layer has 9. In Fig. 4, the index of "obs" means the observed value, the index of "cmd" means the actuator steerage command, and the index of "est"

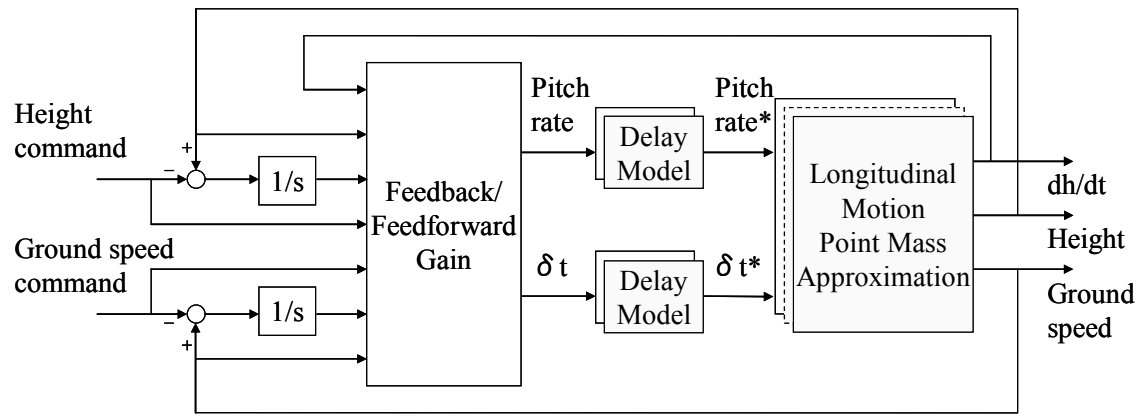

Fig. 3. Block diagram of longitudinal guidance system 


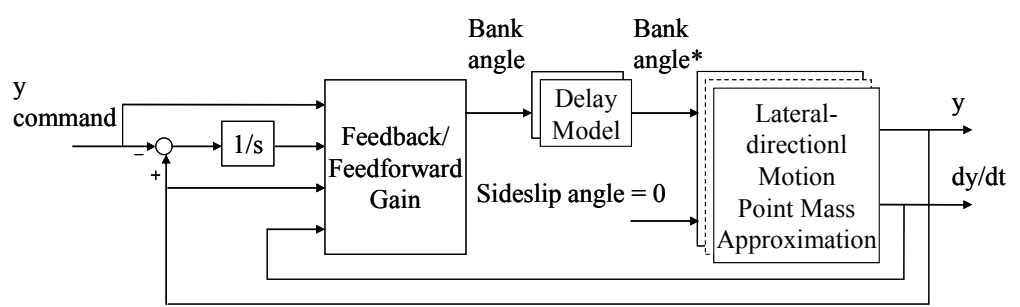

Fig. 4. Block diagram of lateral-directional guidance system

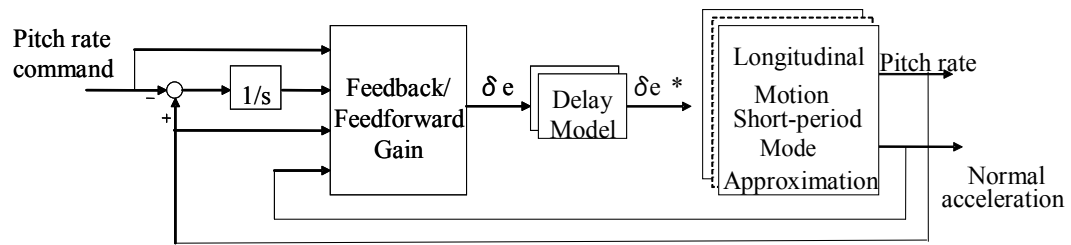

Fig. 5. Block diagram of longitudinal control system

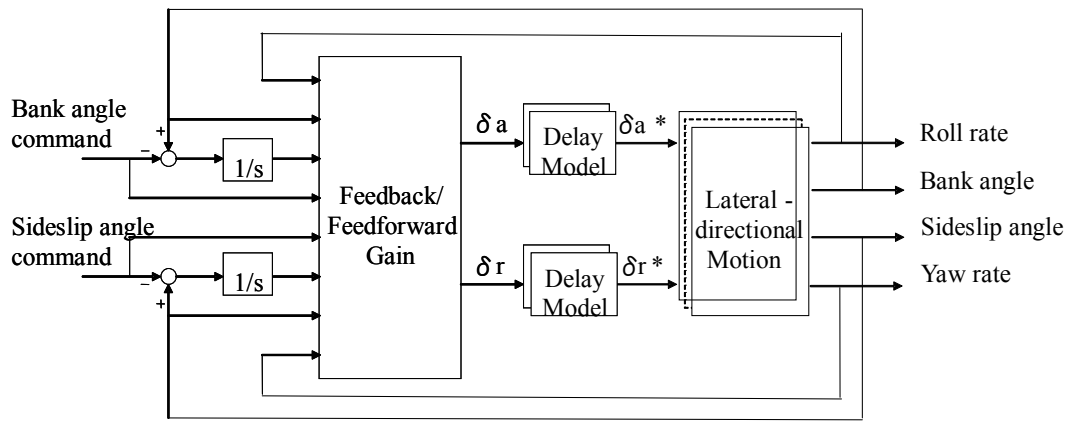

Fig. 6. Block diagram of lateral-directional control system

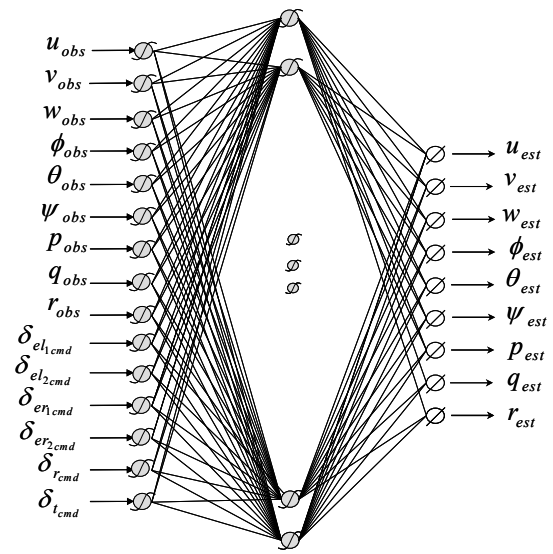

Fig. 7. Structure of estimator neural network 
means the estimated value. The transfer functions of each layer are shown in Eqs. (3) to (5), where each "tansig" and "purelin" means tangent-sigmoid function, linear function shown in Eqs. (6) and (7) respectively. In Eqs. (3) to (5), net i, $_{\text {, }}$ t $_{\mathrm{j}}$, and net $\mathrm{t}_{\mathrm{k}}$ mean the input of input layer, hidden layer, and output layer respectively.

In addition, back propagation (BP) is applied for the learning of neural network. The flight data acquired with the six-degree-of-freedom nonlinear simulation is used as a teach signal.

$$
\begin{gathered}
f_{i}=\operatorname{tansig}\left(\text { net }_{i}\right) \\
f_{j}=\operatorname{tansig}\left(\text { net }_{j}\right) \\
f_{k}=\operatorname{purelin}\left(\text { net }_{k}\right) \\
f(x)=\frac{2}{1+\exp (-2 \cdot x)}-1 \\
f(x)=x
\end{gathered}
$$

\subsection{Detector}

The detector discriminates the influence of fault on the UAV from that of natural disturbance such as gusts of wind by focusing on the impact on the dynamics of the UAV. It uses the error between observed value and estimated value as the information about the dynamics of the UAV. Moreover, the error between actuator steerage command and the real actuator steerage angle is used for the evaluation of the flight condition. The derivative of bank angle is also used.

Because input-output characteristic is unknown, the structure of the detector is three-layer neural network shown in Fig. 8. Input layer has 10 neurons, hidden layer has 20, and output layer has 1. The transfer functions of each layer are shown in Eqs. (8) to (10).

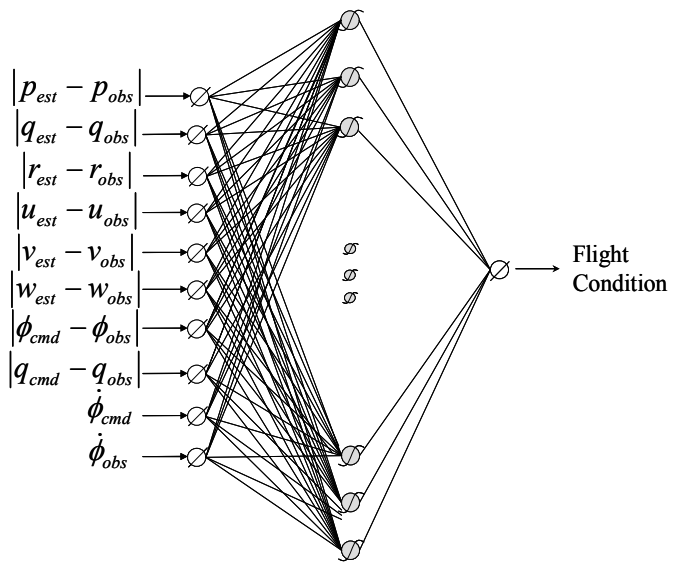

Fig. 8. Structure of detector neural network 


$$
\begin{gathered}
f_{i}=\operatorname{purelin}\left(\text { net }_{i}\right) \\
f_{j}=\operatorname{tansig}\left(\text { net }_{j}\right) \\
f_{k}=\operatorname{purelin}\left(\text { net }_{k}\right)
\end{gathered}
$$

Because there is no explicit teach signal, a genetic algorithm (GA) was applied for the learning of neural network. In GA, 50 individuals that encode the connection weight of a neural network were prepared. Both fitness proportionate and elite selection strategies were used. Moreover, with repeating random crossover and mutation, the individual that had the highest fitness was acquired. 3 cases about gust in different directions and 9 cases about left elevon-1 fault in different angles are used as the simulation case. Both gusts of wind and fault are occurred in horizontal flight. The fitness function is shown in Eq. (11), where $t_{d}$ is the detection time, $t_{\text {failure }}$ is the initiation time of fault, and $a_{d}$ is the constant value of detector for evaluation. In the evaluation, to detect the fault more quickly has higher score. In addition, in the gusts of wind cases, when the detector did false detection, the value of fitness function becomes zero.

$$
J=\left\{\begin{array}{l}
0 \quad\left(t_{d}<t_{\text {failure }}\right) \\
\exp \left(-a_{d} \cdot\left(t_{d}-t_{\text {failure }}\right)\right) \quad\left(t_{d} \geq t_{\text {failure }}\right)
\end{array}\right.
$$

\subsection{Identifier}

The identifier locates where the broken actuator is by using the information of both actuator steerage command and actuator steerage angle. Neural network shown in Fig. 9 is located in each actuator and the location of broken actuator is identified by the outputs of each neural network.

Because input-output characteristic is unknown, the structure of the identifier is three-layer neural network. Input layer has 3 neurons, hidden layer has 18, and output layer has 1 . The

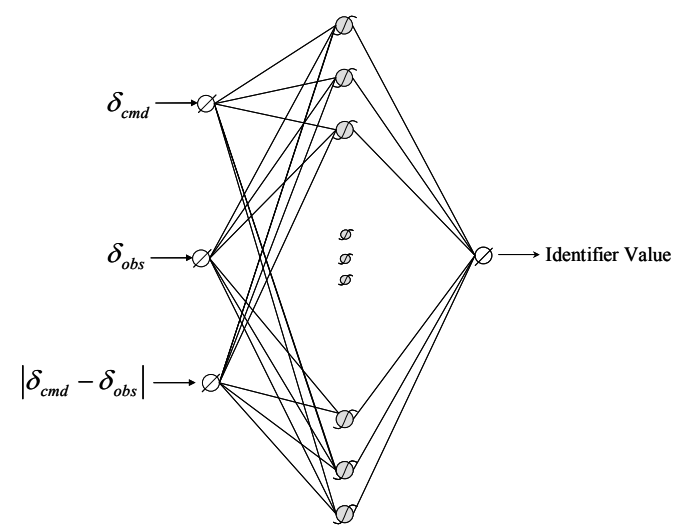

Fig. 9. Structure of identifier neural network 
transfer functions of each layer are shown in Eqs. (12) to (14). GA is applied for the learning of neural network. As the simulation case, 9 cases about left elevon- 1 fault in different angles happened in horizontal flight are used. Equation (15) is the fitness function, where $t_{i}$ is the identification time, $t_{\text {failure }}$ is the initiation time of fault, and $a_{i}$ is the constant value of identifier for evaluation. In the evaluation, to identify the location of broken actuator more quickly has higher score.

$$
\begin{gathered}
f_{i}=\operatorname{purelin}\left(\text { net }_{i}\right) \\
f_{j}=\operatorname{tansig}\left(\text { net }_{j}\right) \\
f_{k}=\operatorname{purelin}\left(\text { net }_{k}\right) \\
J=\left\{\begin{array}{l}
0 \quad\left(t_{i}<t_{\text {failure }}\right) \\
\exp \left(-a_{i} \cdot\left(t_{i}-t_{\text {failure }}\right)\right)\left(t_{i} \geq t_{\text {failure }}\right)
\end{array}\right.
\end{gathered}
$$

\subsection{Distributor}

The distributor switches the distribution matrix by using the outputs of the detector and the identifier. When the distribution matrix was changed, the elevator, aileron, and rudder commands from the control system are divided into 5 actuator commands (left elevon-1, left elevon-2, right elevon-1, right elevon-2, and rudder) to separate the broken actuator. The switching algorithm is to change the command for the broken actuator to zero and to realize the maximum use of the remaining actuators. The structure of the distributor is shown in Fig. 10.

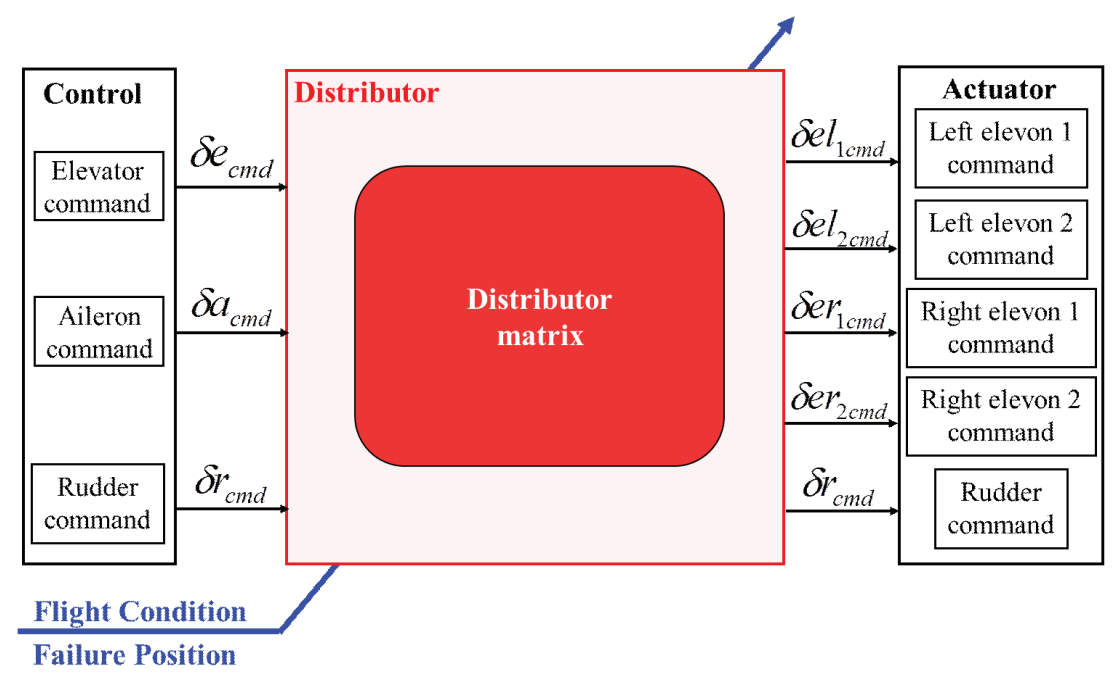

Fig. 10. Structure of distributor 


\subsection{Flight path generator}

The flight path generator is located in parallel with the guidance system. It generates a new flight path which considers both flight stability and following capability of mission trajectory under the condition where the elevon fault is occurred.

In general, there are two turning methods. One is to use a bank angle and the other a sideslip angle. To assure robustness against the rudder fault, the turning method using the bank angle was adopted in the guidance system. On the other hand, to assure robustness against the elevon fault, the turning method using the sideslip was adopted in the flight path generator.

Generally, because drag increases when the sideslip angle is allowed to changes in the turning flight, too much energy is used. However, the emergency situation such as an elevon fault is an exception because keeping the flight stable is more important than saving energy. Therefore, the flight path generator has been designed that enables the sideslip angle to change.

The flight path generator calculates the desired sideslip angle command by using Eq. (16), where $\beta_{r e f_{\text {standard }}}$ is the standard sideslip angle command which achieves the turning flight in mission trajectory. To generate a new flight path by changing the radius adaptively, the flight path generator calculates $K_{\beta}$ depending on the fault level.

$$
\beta_{\text {ref }}{ }^{\prime}=K_{\beta} \cdot \beta_{\text {refstandard }}
$$

Because input-output characteristic is unknown, the structure of the flight path generator is three-layer neural network shown in Fig.11. Input layer has 6 neurons, hidden layer has 1, and output layer has 1 . The input signals of the flight path generator are the signals from both the detector and the identifier which are integrated in a given time. The transfer functions of each layer are shown in Eqs. (17) to (19), where shift $t_{i}$ is the width of parallel shift. Equation (17) is the symmetric double sigmoid function. (Akihiko Shimura \& Kazuo Yoshida, 2001)

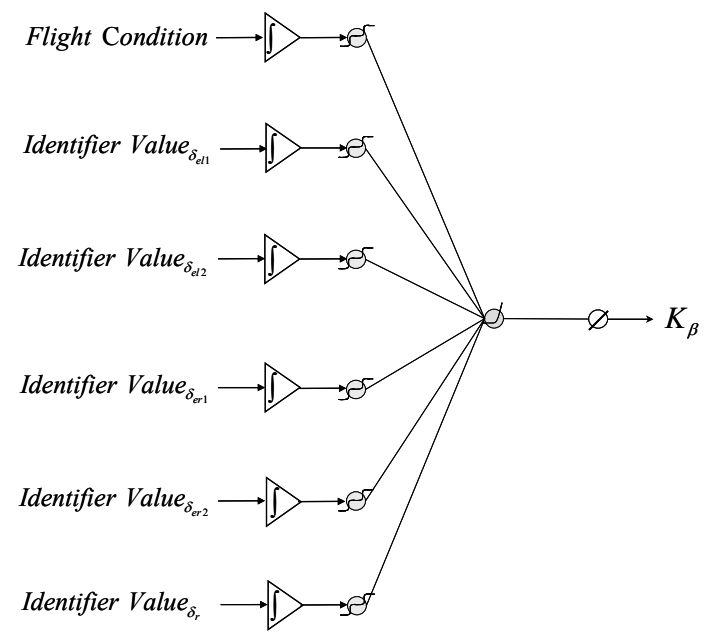

Fig. 11. Structure of flight path generator 


$$
\begin{gathered}
f_{i}=\frac{1}{2}\left\{\operatorname{tansig}\left(\text { net }_{i}-\text { shift }_{i}\right)+\operatorname{tansig}\left(\text { net }_{i}+\text { shift }_{i}\right)\right\} \\
f_{j}=\exp \left(\text { net }_{j}\right) \\
f_{k}=\operatorname{purelin}\left(\text { net }_{k}\right)
\end{gathered}
$$

GA is applied for the learning of neural network. As the simulation case, 7 cases about conducting the turning flight after left elevon- 1 fault in different angles happened in horizontal flight are used. The termination conditions of each simulation case are as follows.
(A) $120<\psi[\operatorname{deg}]<300 \cap x[\mathrm{~m}]<-500$
(B) height $<0.18$
(C) $\alpha[\mathrm{deg}]<-4.9 \cup 29<\alpha[\mathrm{deg}]$
(D) $\beta[\mathrm{deg}]<-9.9 \cup 9.9<\beta[\mathrm{deg}]$

Equation (20) is the fitness function, where $a_{r e f 1}$ and $a_{\text {ref } 2}$ are the constant value for the following capability of mission trajectory. $Y_{\text {ref }}$ is the y-direction target value of mission trajectory. $Y_{r e f}^{\prime}$ is the y-direction target value generated by the flight path generator. time,

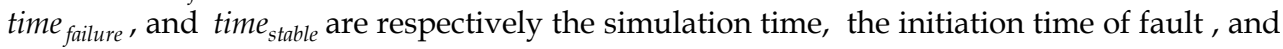
the time when the error value between the real height and that of mission trajectory is controlled within the constant value. In the evaluation, both the following capability of mission trajectory and the flight stability are evaluated.

In addition to Eq. (20), the termination conditions are also evaluated. When the simulation was stopped because of the termination condition except for (A), the value of fitness function becomes zero because the stability is lost.

$$
\begin{array}{r}
J=a_{r e f 1} \cdot \exp \left(-a_{r e f 2} \cdot\left|Y_{r e f}{ }^{\prime}-Y_{\text {ref }}\right|\right) \\
+\exp \left(\frac{\text { time }_{\text {stable }}}{\left.(\text { time-failure time })_{\text {fitur }}\right)}\right)
\end{array}
$$

\section{Numerical simulation}

\subsection{Simulation condition}

The effectiveness of the proposed intelligent fault-tolerant flight control system was verified with the six-degree-of-freedom nonlinear simulation. The airframe model, external environment model, and guidance/control law were considered as a mathematical model in the simulation. In the airframe model, the actuator characteristic was expressed using the second order time delay model with restrictions of position and velocity. In addition, the characteristic of sensor was assumed to be ideal that there were no errors in both static and dynamic conditions. As the external environment model, only wind was used. The constant wind model was constructed by using the MIL-F-9490D method applied to the ALFLEX simulation. (NAL/NASDA ALFLEX Group, 1994) It considered the difference of the 
airframe size by multiplying the scale-dependent constant value. The actuator-fixed fault such as Lock-in-place, Hard-over and Float was adopted as the actuator fault model. (Jovan D. Boskobic et al, 2005)

As the mission trajectory, turning above devastated district in constant height to observe was applied. It is shown in Fig. 12. In this mission, the UAV flaw at the height of $30 \mathrm{~m}$ in the velocity of $20 \mathrm{~m} / \mathrm{s}$ and the constant wind was from $+x$ direction. The gusts of wind was expressed by changing the scale-dependent constant value of constant wind in 3 seconds. (Kohichiroh Yoshida et al, 1994) In addition, not only the learned fault, left elevon-1 fault, but also non-learned fault, rudder fault, was considered. The conditions of fault and gust are represented in Table 2.

In the simulation, the proposed intelligent fault-tolerant flight control system and the flight control system designed by MDM/MDP method were compared.

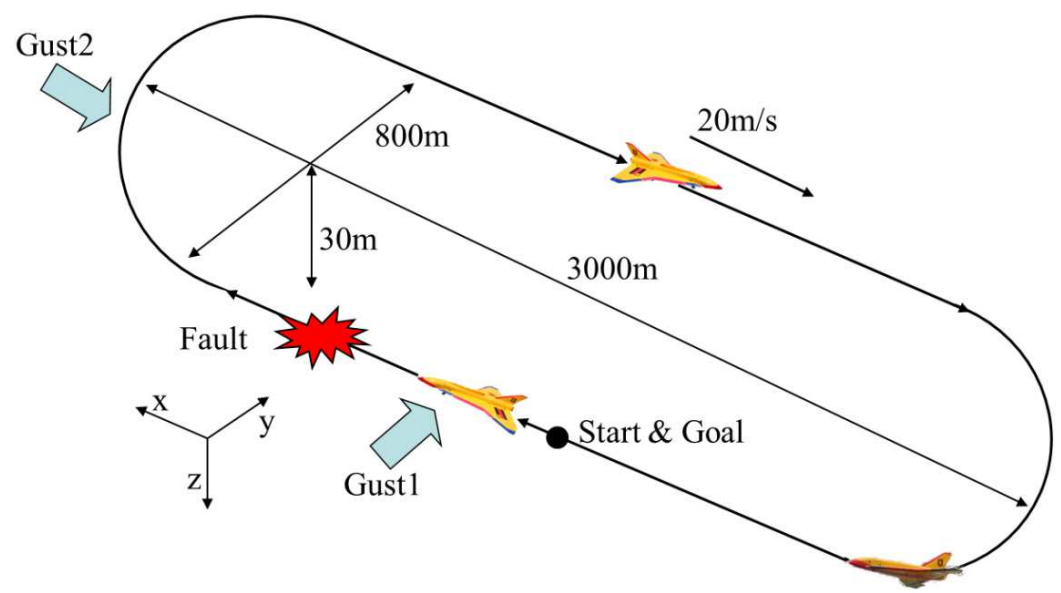

Fig. 12. Mission trajectory

\begin{tabular}{c|c|c}
\hline \hline Condition & Time & Direction \\
\hline Gust 1 & $15 \mathrm{~s}$ & From y minus \\
\hline Failure & $30 \mathrm{~s}$ & \\
\hline Gust2 & $90 \mathrm{~s}$ & From $x$ plus
\end{tabular}

Table 2. Conditions of disturbance

\subsection{Simulation results}

In this section, the simulation results under the condition shown in section 5.1 are represented.

First, Figs. 13 to 19 respectively show the results under the conditions where the left elevon1 was fixed at 9 degree for the flight trajectory, the time history of bank angle, sideslip angle, and actuator steerage. In addition, Table 3 shows the effective area.

Second, the results for detection, identification, and accommodation are shown. The output of the detector and the identifier are respectively shown in Figs. 20 and 21. Figure 22 shows the relationship between the fixed angle of broken elevon and the y-direction target value 
generated by the flight path generator. Moreover, the coherence functions between the observed value and the estimated value for velocity $u$ and angular velocity $q$ are compared under the conditions of a fault and gust of wind in Figs. 23 and 24.

Finally, Figs. 25 and 26 show the results under the condition where the rudder was fixed at 8 degree for the flight trajectory and the time history of actuator steerage.

\subsection{Evaluation}

From the results in Figs. 13 to 19, we confirmed how each method deals with the fault in which the elevon is fixed at the angle.

The conventional system generates a bank angle command and achieves a turning flight by using an elevon. On the other hand, the proposed flight control system stabilizes the airframe by using redundant elevon in horizontal flight as soon as the fault happens. After that, it generates a sideslip angle command and achieves a turning flight by using a rudder.

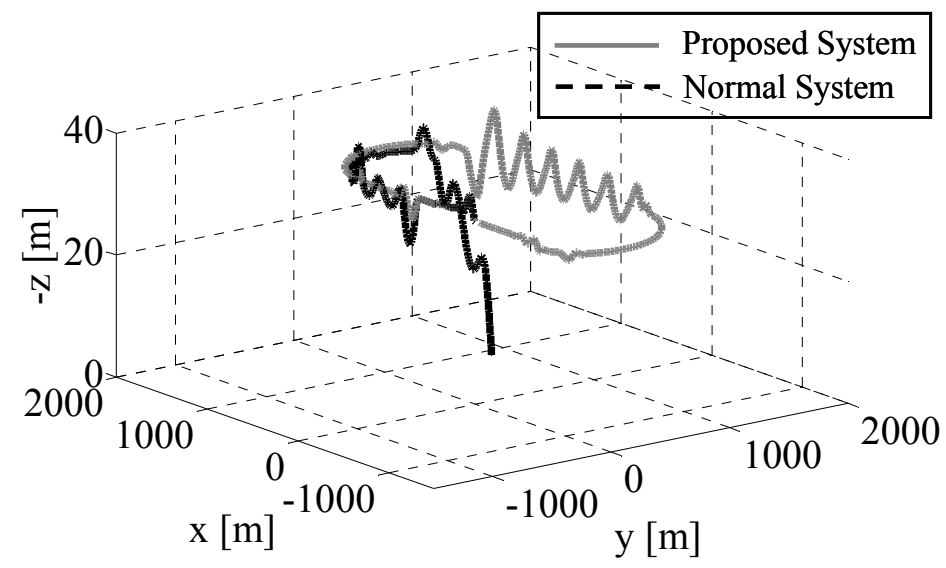

Fig. 13. Flight trajectory (left elevon-1 fault)

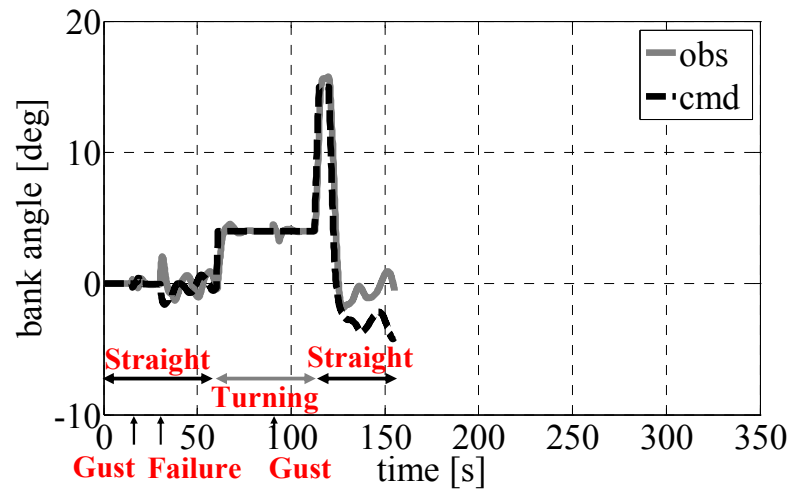

Fig. 14. Time history of bank angle (normal system) 


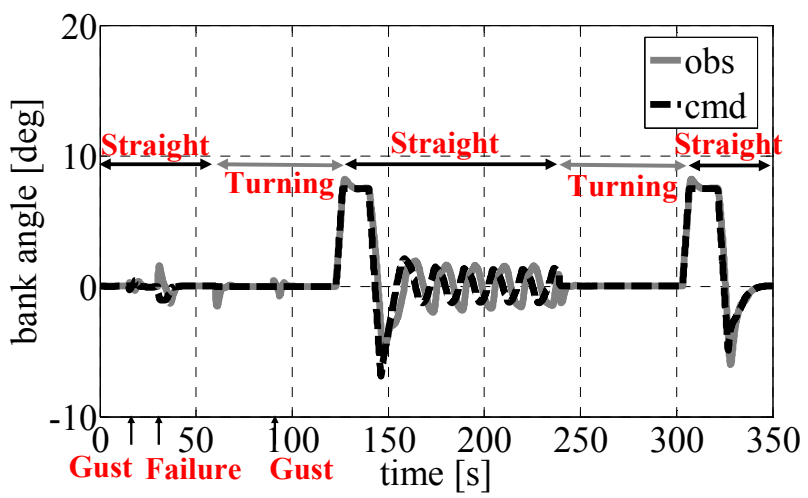

Fig. 15. Time history of bank angle (proposed system)

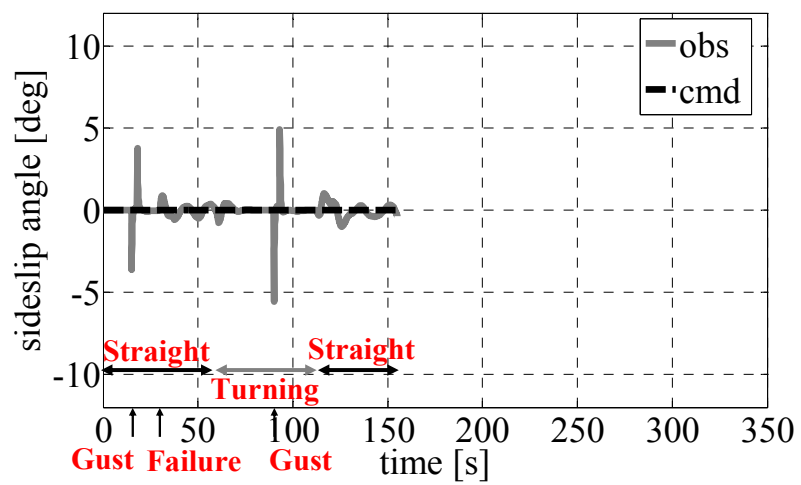

Fig. 16. Time history of sideslip angle (normal system)

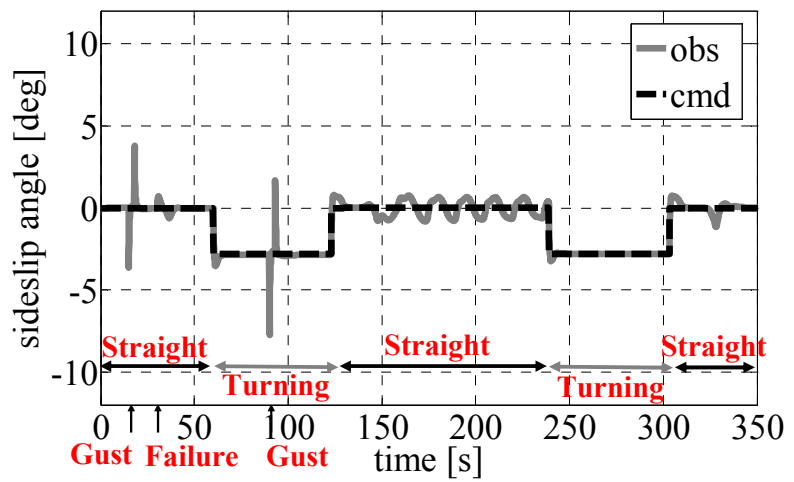

Fig. 17. Time history of sideslip angle (proposed system) 


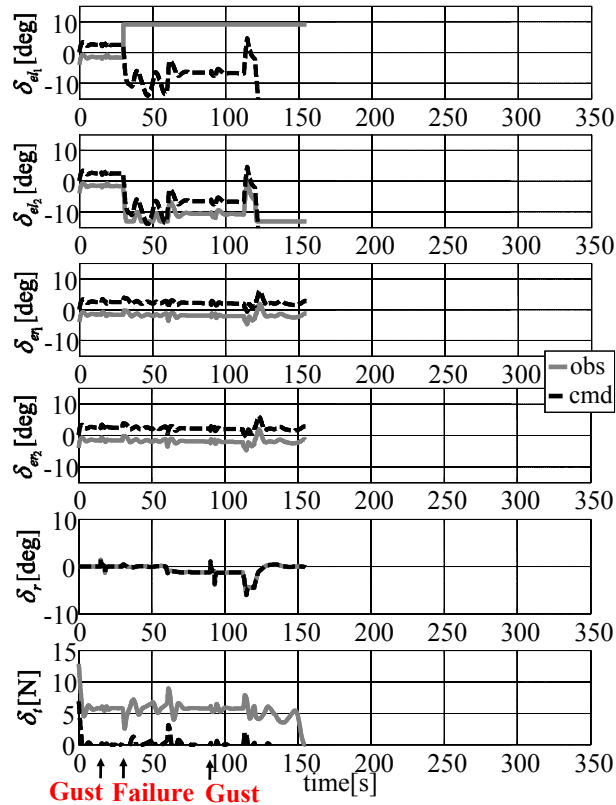

Fig. 18. Time history of actuator steerage (normal system)

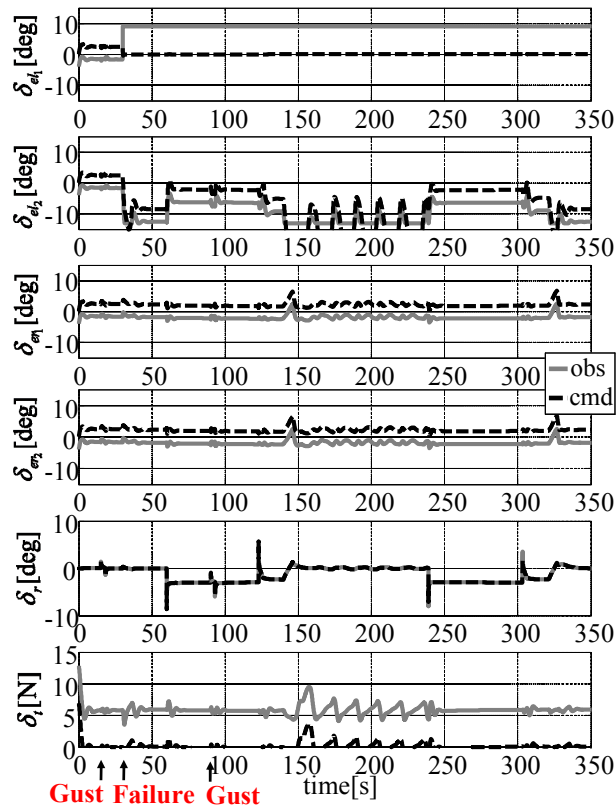

Fig. 19. Time history of actuator steerage (proposed system) 


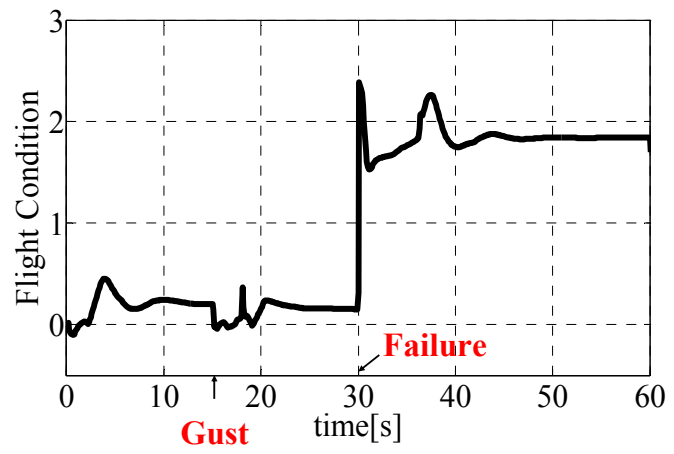

Fig. 20. Output of detector neural network

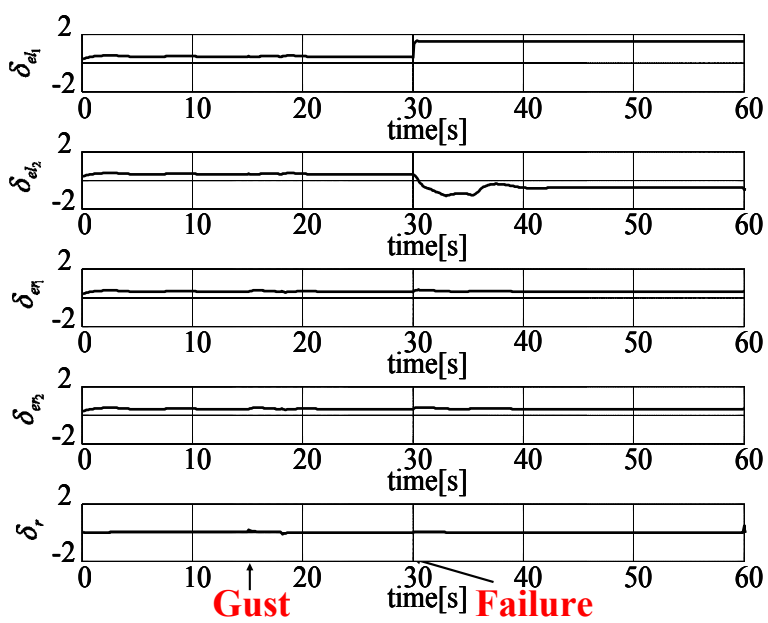

Fig. 21. Output of identifier neural network

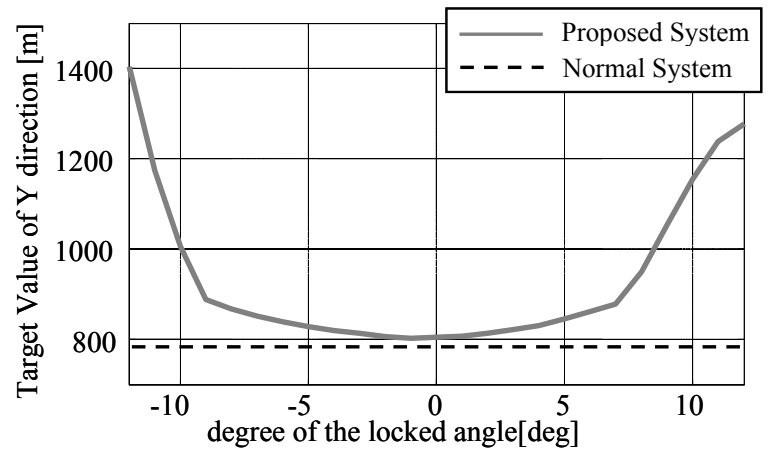

Fig. 22. Target value generated by flight path generator 


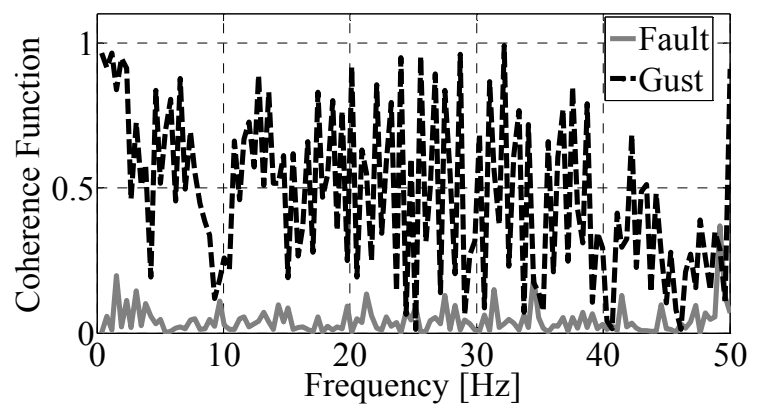

Fig. 23. Coherence function, $u$

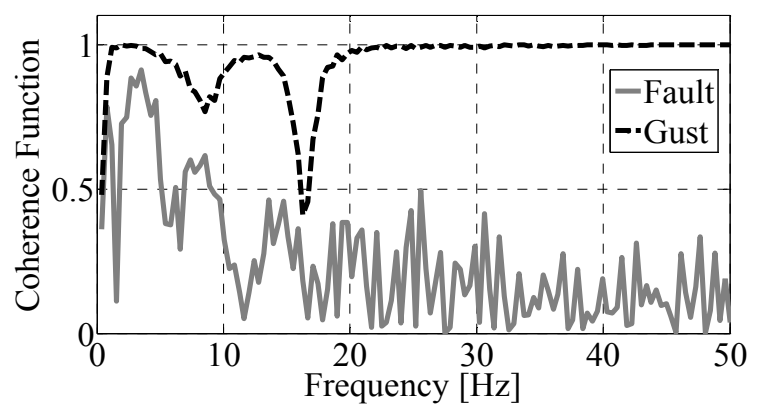

Fig. 24. Coherence function, $q$

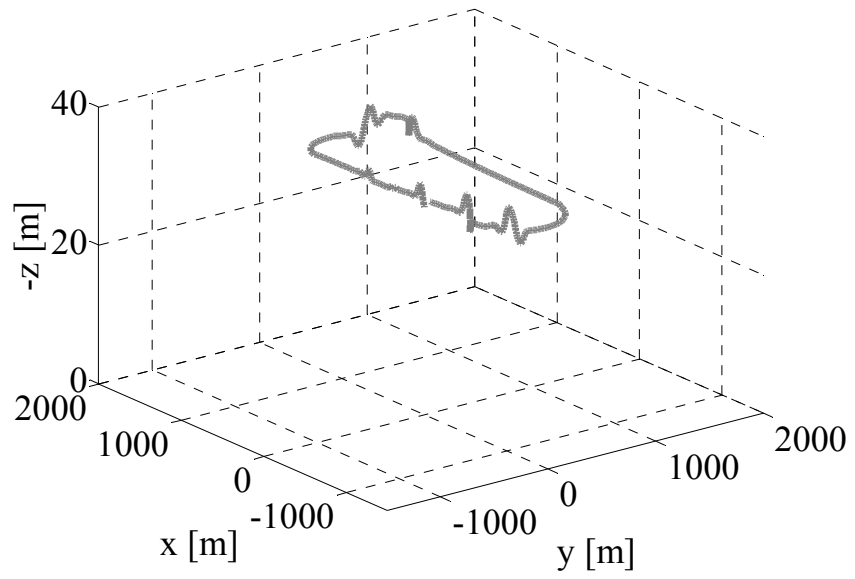

Fig. 25. Flight trajectory (rudder fault) 


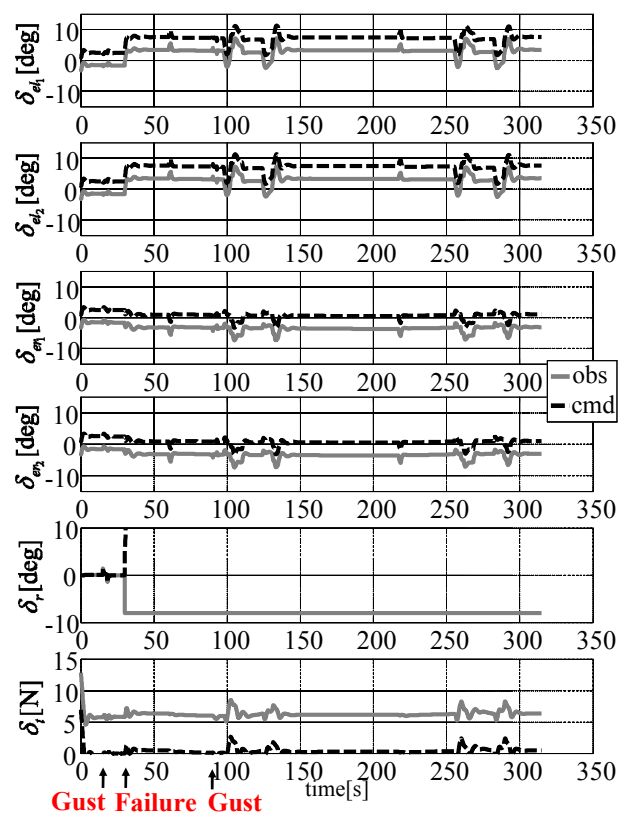

Fig. 26. Time history of actuator steerage (rudder fault)

\begin{tabular}{c|c|c}
\hline \hline Fault position & Elevon & Rudder \\
\hline Range of movement [deg] & $-13 \sim 13$ & $-8 \sim 8$ \\
Effective area[deg] & $-13 \sim 9$ & $-8 \sim 8$
\end{tabular}

Table 3. Effective area of proposed system 
The results in Figs. 13, 15, 17, and 19, confirm that the vibration motion is generated in the horizontal flight after turning flight by using the proposed method. This vibration frequency is about $0.067 \mathrm{~Hz}$. This is because the resonation with the vibration occurs at the longitudinal short cycle mode and the lateral-directional dutchroll mode when the turning flight is changed to the horizontal flight in order to deal with the fault. However, this vibration fits into the stable area of both an attack angle and a sideslip angle that is established when designed and shown in section 4.6 as the termination conditions. Therefore, the vibration is considered to be an allowable range.

From the results in Figs. 25 and 26, we confirmed that the proposed flight control system generates a bank angle command and achieves a turning flight by using an elevon when a rudder fault happens.

These results confirm that the proposed system can detect, identify and accommodate both learned and non-learned faults.

From the simulation results, we confirmed that the proposed flight control system can stabilize the airframe in fault situations shown in Table 3.

Figure 20 shows the output of a detector which means the evaluation value of a flight condition. We confirmed that the detector can distinguish the fault from the gust of wind. The flight control system can distinguish between the fault and the gusts from various directions because a number of directional gusts are considered in the learning of neural network. Figures 23 and 24 show that the gust has a wider range of frequency where the coherence function takes the value of approximately 1 than the fault. If the disturbance is estimated, the motion of the system is the same as the model assumed when the control system is designed. On the other hand, the motion of the system with the fault is different from the assumed model. Therefore, the proposed model-based detector can accurately detect faults.

Figure 21 shows the output of an identifier which means the evaluation value of the fault position. It was confirmed that the proposed identifier can identify the fault position because only the broken actuator indicates the abnormal value.

Figure 22 shows the performance of a flight path generator. The horizontal axis indicates a fixed angle of a broken elevon and the vertical axis indicates a new target value of $y$ direction that is calculated by the flight path generator. The results confirm that the higher the level of a fault, the gentler the turning based on a new target value generated by the flight path generator. In this research, the actuator error between the stable and the broken conditions means the fault level. Moreover, the error from a mission trajectory is considered in the evaluation function. Therefore, the proposed flight control system can generate a suitable target value of turning in accordance with the situation.

The proposed flight control system focuses on the change in dynamics caused by a fault. It is designed by considering the elevon fault that enormously influences the airframe because an elevon plays the roles of both an aileron and an elevator. The simulation results confirm the proposed system can perform well in both learned and non-learned fault situations.

\section{Conclusion}

This research aimed at proposing an intelligent fault-tolerant flight control system for an unmanned aerial vehicle (UAV). In particular, the flight control system was developed that 
has estimator, detector, identifier, distributor, and flight path generator. The proposed system distinguishes a fault from a disturbance like a gust of wind and automatically generates a new flight path suited to the fault level. To verify the effectiveness of the proposed method, a six-degree-of-freedom nonlinear simulation was carried out. In the simulation, we assumed that the fault in left elevon-1, which was learned in designing each neural network, or the fault in the rudder, which was not learned, would be generated in a horizontal flight. The simulation results confirm that the proposed flight control system can detect, identify and accommodate the fault and keep a flight stable. Moreover, the proposed system can distinguish a fault from a gust and keep a flight stable automatically. It is expected that the proposed design method can be used in broader flight areas by expanding the learning area.

\section{References}

Akihiko Shimura and Kazuo Yoshida, Non-Linear Neuro Control for Active Steering for Various Road Condition, The Japan Society of Mechanical and Engineers, Vol. 67, No. 654(2001), pp. 407-413.

Brian L. Steavens and Frank L. Lewis, Aircraft Control and Simulation 2nd Edition, JOHN WILEY \& SONS, INC. (2003)

Guillaume Ducard and Hans P. Geering, Efficient Nonlinear Actuator Fault Detection and Isolation System for Unmanned Aerial Vehicles, AIAA, Journal of Guidance, Control, and Dynamics, Vol. 31, No.1 (2008), pp. 225-237.

Jovan D. Boskovic, Sarah E. Bergstrom , and Raman K. Mehra, Robust Integrated Flight Control Design Under Failures, Damage, and State-Depenndent Disturbances, AIAA, Journal of Guidance, Control, and Dynamics, Vol. 28, No.5 (2005), pp. 902-916.

Kanichiro Kato, Akio Oya, and Kenzi Karasawa, Introduction of Aircraft Dynamics, University of Tokyo Press, (1982).

Kohichiroh Yoshida, kazumichi Mototsuna and Yasushi Kumakura, Elementary knowledge of marine technology, Seizandou,(1994)

Masaki Takahashi, Teruma Narukawa and Kazuo Yoshida, Robustness and Fault-Tolerance of Cubic Neural Network Intelligent Control Method : Comparison with Sliding Mode Control, The Japan Society of Mechanical and Engineers, Vol. 69, No. 682(2003), pp. 1579-1586.

Mohammad Azam, Krishana Pattipati, Jeffrey Allanach, Scott Poll, and Ann Patterson-Hine, In-flight Fault Detection and Isolation in Aircraft Flight Control Systems, Aerospace Conference, 2005 IEEE, (2005), pp. 3555- 3565.

NAL/NASDA ALFLEX Group, Flight simulation model for Automatic Landing Flight Experiment (Part I : Free Flight and Ground Run Basic Model), Technical Report of National Aerospace Laboratory, Vol. 1252 (1994).

Taro Tsukamoto, Masaaki Yanagihara, and Takanobu Suito, Feasibility Study of Lateral/Directional Control of Winged Re-entry Vehicle with Split Elevons, Technical Report of National Aerospace Laboratory, Vol. 1379 (1999). 
Toshinari Shiotsuka, Kazusige Ohta, Kazuo Yoshida and Akio Nagamatsu, Identification and Control of Four-Wheel-Steering Car by Neural Network, The Japan Society of Mechanical and Engineers, Vol. 59, No. 559(1993), pp. 708-713.

Tsuyoshi Hatake, Junichiro Kawaguchi, and Tatsushi Izumi, Control in Aerospace, CORONA PUBLISHING CO., LTD. (1999). 


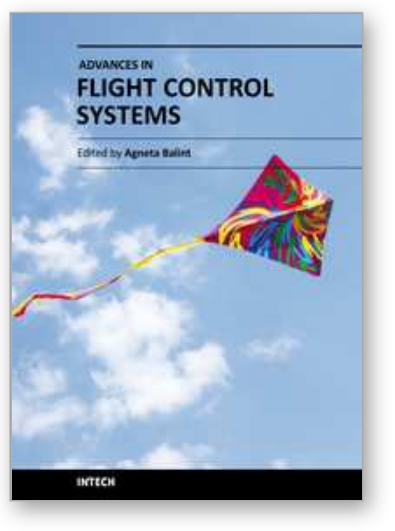

\author{
Advances in Flight Control Systems \\ Edited by Dr. Agneta Balint
}

ISBN 978-953-307-218-0

Hard cover, 296 pages

Publisher InTech

Published online 11, April, 2011

Published in print edition April, 2011

Nonlinear problems in flight control have stimulated cooperation among engineers and scientists from a range of disciplines. Developments in computer technology allowed for numerical solutions of nonlinear control problems, while industrial recognition and applications of nonlinear mathematical models in solving technological problems is increasing. The aim of the book Advances in Flight Control Systems is to bring together reputable researchers from different countries in order to provide a comprehensive coverage of advanced and modern topics in flight control not yet reflected by other books. This product comprises 14 contributions submitted by 38 authors from 11 different countries and areas. It covers most of the currents main streams of flight control researches, ranging from adaptive flight control mechanism, fault tolerant flight control, acceleration based flight control, helicopter flight control, comparison of flight control systems and fundamentals. According to these themes the contributions are grouped in six categories, corresponding to six parts of the book.

\title{
How to reference
}

In order to correctly reference this scholarly work, feel free to copy and paste the following:

Yuta Kobayashi and Masaki Takahashi (2011). Design of Intelligent Fault-Tolerant Flight Control System for Unmanned Aerial Vehicles, Advances in Flight Control Systems, Dr. Agneta Balint (Ed.), ISBN: 978-953-307218-0, InTech, Available from: http://www.intechopen.com/books/advances-in-flight-control-systems/design-ofintelligent-fault-tolerant-flight-control-system-for-unmanned-aerial-vehicles

\section{INTECH}

open science | open minds

\section{InTech Europe}

University Campus STeP Ri

Slavka Krautzeka 83/A

51000 Rijeka, Croatia

Phone: +385 (51) 770447

Fax: +385 (51) 686166

www.intechopen.com

\section{InTech China}

Unit 405, Office Block, Hotel Equatorial Shanghai

No.65, Yan An Road (West), Shanghai, 200040, China

中国上海市延安西路65号上海国际贵都大饭店办公楼 405 单元

Phone: +86-21-62489820

Fax: $+86-21-62489821$ 
(C) 2011 The Author(s). Licensee IntechOpen. This chapter is distributed under the terms of the Creative Commons Attribution-NonCommercialShareAlike-3.0 License, which permits use, distribution and reproduction for non-commercial purposes, provided the original is properly cited and derivative works building on this content are distributed under the same license. 